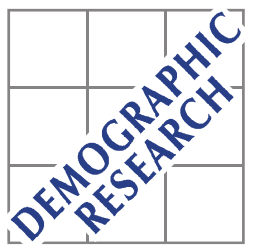

Demographic Research a free, expedited, online journal

of peer-reviewed research and commentary in the population sciences published by the Max Planck Institute for Demographic Research

Konrad-Zuse Str. 1, D-18057 Rostock · GERMANY

www.demographic-research.org

DEMOGRAPHIC RESEARCH

VOLUME 27, ARTICLE 3, PAGES 53-84

PUBLISHED 10 JULY 2012

http://www.demographic-research.org/Volumes/Vol27/3/

DOI: 10.4054/DemRes.2012.27.3

Research Article

\title{
Grandparenting and mothers' labour force participation: A comparative analysis using the generations and gender survey
}

Arnstein Aassve

Alice Goisis

\author{
Bruno Arpino
}




\section{Table of Contents}

1 Introduction $\quad 54$

$2 \quad$ Literature review $\quad 56$

$3 \quad$ Theoretical perspectives 58

3.1 Systems of intergenerational support 58

$\begin{array}{lll}3.2 & \text { Preferences for grandparenting } & 61\end{array}$

$4 \quad$ Empirical strategy $\quad 64$

4.1 Data 64

$\begin{array}{lll}4.2 & \text { Methodology } & 67\end{array}$

$5 \quad$ Results $\quad 69$

$6 \quad$ Concluding remarks $\quad 76$

$7 \quad$ Acknowledgements $\quad 78$

$\begin{array}{ll}\text { References } & 79\end{array}$ 


\title{
Grandparenting and mothers' labour force participation: A comparative analysis using the generations and gender survey
}

\author{
Arnstein Aassve $^{1}$ \\ Bruno Arpino ${ }^{2}$ \\ Alice Goisis $^{3}$
}

\begin{abstract}
BACKGROUND

It is well known that the provision of public childcare plays an important role for women labour force participation and its availability varies tremendously across countries. In many countries, informal childcare is also important and typically provided by the grandparents, but its role on mothers' employment is not yet well understood. Understanding the relationship between labour supply decisions and grandparental childcare is complex. While the provision of grandparental childcare is clearly a function of the social and institutional context of a country, it also depends on family preferences, which are typically unobserved in surveys.
\end{abstract}

\section{OBJECTIVE}

We analyze the role of informal childcare provided by grandparents on mothers' labour force participation keeping unobserved preferences into account.

\section{METHODS}

Bivariate probit models with instrumental variables are estimated on data from seven countries (Bulgaria, France, Georgia, Germany, Hungary, Russia and The Netherlands) drawn from the Generations and Gender Survey.

\section{RESULTS}

We find that only in some countries mothers' employment is positively and significantly associated with grandparents providing childcare. In other countries, once we control for unobserved preferences, we do not find this effect.

\footnotetext{
${ }^{1}$ Bocconi University, Milan. E-mail: arnstein.aassve@unibocconi.it.

${ }^{2}$ Department of Political and Social Sciences and Research and Expertise Center for Survey Methodology, Universitat Pompeu Fabra. E-mail: bruno.arpino@upf.edu.

${ }^{3}$ London School of Economics. E-mail: A.Goisis@lse.ac.uk.
} 


\section{CONCLUSIONS}

The role of grandparents is an important element to reconcile work and family for women in some countries. Our results show the importance of considering family preferences and country differences when studying the relationship between grandparental childcare and mothers' labour supply.

\section{COMMENTS}

Our results are consistent with previous research on this topic. However, differently from previous studies, we conduct separate analyses by country and show that the effect of grandparental childcare varies considerably. The fact that we also include in the analyses Bulgaria, Hungary, Russia and Georgia is an important novelty as there are no studies on this issue for these countries.

\section{Introduction}

One of the most remarkable transformations of Western societies in recent decades is the rise in female labour force participation (Vlasblom 2004). Every indication suggests that female labour force participation is here to stay, and most likely it will increase in the years to come. Perhaps the most important change female employment entails is a shift in the gender balance in households and societies, as the traditional breadwinner model is rapidly disappearing in Western countries (McDonald 2000). The rise in female employment is also vitally important for the sustainability of social protection systems, especially in the context of rapid population ageing (Pagani and Marenzi 2008). There is consequently considerable interest in understanding the role of female labour force participation in Western societies.

Rising participation rates are closely intertwined with demographic behaviour. In some countries, especially where state welfare and support is weaker, increasing female labour force participation is accompanied by low fertility rates. In contrast, in those countries where fertility has remained high we also find stronger state support towards childcare (Billari and Kohler 2004; McDonald 2000). Importantly, these are the countries where female labour force participation is the highest. Availability of public childcare varies tremendously between countries (Rindfuss and Brauner-Otto 2008) and the provision of public childcare clearly plays an important role. That said, in many countries informal childcare is also important and typically provided by grandparents, but its pattern and role in mothers' employment is not well understood. 
The advancement of societies has involved substantial changes in family life and its organization, of which demographic transformations have been an important driver. The emergence of smaller families and increased life expectancy have altered the old forms of family relationships, thereby sparking a wealth of new studies (see, for example, Atkinson et al. 1986; Rossi and Rossi 1990). Increased life expectancy coupled with fertility decline has generated a new family structure, often described as multi-generation or "beanpole families", where, over time, vertical relationships among relatives have become stronger (Giarrusso et al. 1995; Brannen et al. 2004). Put in a different way, kinship networks are becoming "tall and lean" (Saraceno 2008). In light of these developments it is important to ask what role grandparents have in terms of providing support to younger generations.

This paper focuses on the relationship between grandparenting and mothers' labour force participation using data on seven countries from the Generations and Gender Survey (GGS). We consider how grandparents' childcare provision affects mothers' labour supply in Bulgaria, France, Georgia, Germany, Hungary, the Netherlands, and Russia. There are important intergenerational relationships that (may) matter for mothers' labour supply decisions, but where the effects may depend on the considered context and institutional setting. We argue that the role of grandparenting differs across these countries, but not necessarily in the way one would expect. For instance, public childcare in France is extensive, which is reflected in lower rates of grandparenting. However, this is not to say that grandparenting is less important. For a relatively small proportion of parents and for a variety of reasons, grandparenting is critically important in enabling the mothers to work. In this setting grandparenting is a mechanism for helping the mother (Hagestad 2006). In other settings, where public childcare is scarce and grandparenting is more common and often seen as the norm for childcare, grandparenting is geared towards helping the children (Hagestad and Herlofson 2010). The fact that we also consider countries such as Russia, Hungary, Bulgaria, and Georgia is another important novelty of this analysis, as there are no studies on this issue for these countries. These countries are experiencing tremendous changes to their societies that influence their work-style patterns and intra-family dynamics.

In our empirical analysis we start by considering a simple framework for how labour market participation relates to the provision of childcare undertaken by grandparents. As already argued, this very much depends on the contextual setting. However, the extent to which grandparents provide actual childcare to their grandchildren also depends on their preferences for doing so, which in turn is a function of the context. The policies embedded in the different welfare regimes are therefore highly relevant. As pointed out by Saraceno (2008), "Welfare State policies are not only policies of age and of obligation between social generations. They are also forms of 
regulating obligations within family generations, through measures concerning maternity and parental leaves, child benefits, and access to education." Country-specific characteristics concerning intergenerational obligations may act as an incentive (or disincentive) to the development of specific forms of welfare arrangement. Thus, social actions affect and are affected by family preferences. It is no surprise that countries with similar welfare systems have analogous intergenerational exchange patterns. The idea is that the geography of welfare regimes in many respects corresponds to the geography of structures, institutions, and values, which in turn relates to family solidarity (Reher 1998).Mothers' labour supply and grandparents providing childcare are presumably the outcome of a process of negotiation between the two generations. For instance, a grandparent who has conservative or traditional preferences in family life, which would be more prevalent in traditional societies, might be less favourable towards the use of public childcare and may be more positively inclined to help out in childcare duties. At the same time, given traditional preferences, he or she might be less supportive of mothers participating in the labour market. Since the two generations interact, the traditional preferences of the grandparents may also negatively affect the mother's labour supply decision. Statistically speaking we are encountering a classic omitted variable bias problem, the key reason being that we cannot observe these preferences directly, whereas grandparents' preferences do have an impact on both their actual provision of childcare and the mother's employment. Our strategy for controlling for unobserved preferences towards grandparenting follows a simultaneous equation approach. That is, we estimate mothers' labour force decision controlling for the unobserved preferences of grandparents to provide childcare. Our estimates are discussed within the framework and discussion generated by the recently established Multilinks database which provides country information about welfare provision, particularly in light of intergenerational relationships.

\section{Literature review}

The provision of childcare along intergenerational lines has received a good deal of attention in the US (see, for example, Pebley and Rudkin 1999; Fuller-Thomson and Minkler 2001; Hayslip and Kaminski 2005; Vandell et al. 2003) but considerably less in Europe, where comparative analyses are limited, partly due to lack of suitable data. However, Europe represents an interesting case study for intergenerational relationships, especially since European countries differ in welfare provision, demographic and economic behaviours, and family culture. There is consequently a growing and recent literature that considers the role of intergenerational relationships in Europe. This literature reports that there is no indication of a decline in 
intergenerational relations (e.g., Gray 2005; Hank 2007). Substantial transfers of resources from parents to their offspring still take place and often occur in the form of childcare provided by grandparents. Most of the studies argue that this form of downward time transfer from older to younger generations occurs predominantly because of a 'need' which may derive from a range of factors, including family structure (i.e., lone parenthood) or financial difficulties (i.e., unaffordable private childcare). However, these needs may be mediated by the institutional settings where parents live, and by the characteristics of the grandparents themselves (i.e., age and health status).

Recent studies stress the importance of adopting a comparative perspective, thereby accounting for differences in institutional welfare provision. As is well known, welfare systems differ substantially across Europe (Esping-Andersen 1990, 1999), and this might matter for intergenerational transfers in the form of childcare. In a system that provides broad and universal public childcare (such as the Social Democratic system of the Scandinavian countries), the need for grandparenting is perhaps more limited. In contrast, the need for grandparenting might be much stronger in familistic welfare systems, such as those of the Mediterranean countries. In the former, grandparenting might be seen as a way to help parents in immediate need of assistance, whereas in the latter grandparenting might be considered as a permanent form of rearing children. In this sense, in familistic welfare systems grandparents act as "children helpers", whereas in social democratic countries they act as "parent helpers" (Hagestad and Herlofson 2010)

However the empirical evidence is somewhat mixed. Hank and Buber (2009) and Albertini et al. (2007), both using data from the Survey of Health, Ageing and Retirement in Europe (SHARE), show that the probability of providing care is generally higher among Nordic countries and France, whereas it is lower in Mediterranean countries. On the other hand, if Mediterranean grandparents do help in childcare they do so more regularly and intensively. Against the backdrop of these findings it is not clear whether it is wise to dichotomize welfare systems according to 'weak' versus 'strong' family ties. A possible explanation behind these results is that in northern countries public childcare services foster maternal employment and so the role of grandparents is complementary to the public childcare arrangements. Conversely, in Southern Europe the lack of public day care for children inhibits maternal employment and there is only limited demand for grandparents to step in, because mothers tend to be full-time carers. If, however, a Mediterranean mother decides to seek gainful employment, she has to rely on grandparents' support on a regular basis, thereby making grandparents an important source of care for the children.

Starting from the 1990s several papers, especially by economists, have begun to pay attention to the importance of the impact of intergenerational links on mothers' 
labour market participation. Ermisch and Ogawa (1996) were among the first to assess the impact of intergenerational solidarity on the combination of motherhood and work by exploring the link between intergenerational co-residence and the labour supply of young women. They do indeed show a positive impact of intergenerational co-residence on female labour force participation, highlighting a clear link between downward time transfers and work decisions of the recipient. Building on this work a range of studies started focussing on the importance of time transfers from parents to adult children, highlighting their positive effect on the participation rates of the latter (Chiuri 2000; Del Boca 2002; Bratti 2003; Pagani and Marenzi 2008; Arrondel and Masson 2006; Dimova and Wolff 2008; Dimova and Wolff 2011). As highlighted by Guzman (1999), in addition to economic and practical needs, childcare preferences also play an important role in explaining time transfers from grandparents. However these preferences are usually unobserved, and this implies that grandparents' childcare is endogenous with respect to mothers' labour supply, even after having controlled for covariates. The paper of Dimova and Wolff (2011) is, to the best of our knowledge, the only one to study the impact of private transfers on the career choice of women by taking a comparative perspective and addressing the endogeneity issue. However, in contrast to their work, our paper explicitly discusses the various sources of endogeneity that might affect the estimates. Moreover, we discuss why the strength and direction of bias caused by unobserved preferences depend on the country context.

\section{Theoretical perspectives}

There are several reasons why it is important to consider the context in which grandparenting and labour supply decisions occur. Institutional and welfare state systems provide different incentives for individual and family behaviours, while also shaping their interactions. Moreover, individual behaviours will also in turn influence policies: a society characterized by strong intergenerational transfers will not foster the development of generous support policies and higher coverage in childcare services.

\subsection{Systems of intergenerational support}

European countries represent different societal systems in the provision of childcare services. This also suggests that states differ to a great extent in the way they define, regulate, support, and have expectations of the flow of resources between generations (Keck, Hessel, and Saraceno 2009). Intergenerational transfers are shaped and implemented in the interplay between collective and private forms of provision: they 
are embedded in a "welfare mix" (Saraceno and Keck 2008). As in many other comparative studies, it is useful to think of European countries as clustering into different intergenerational support systems. Whereas the Esping-Andersen (1990) classification is often used for welfare categorization, it is not clear that this is also suitable in the context of intergenerational support. As Saraceno and Keck (2008) discuss, the Esping-Andersen typology was developed primarily in relation to the welfare state, while the nature of intergenerational relations within families depends both on civil law regulations, aspects of the schooling system, and, not least, transfer systems (such as maternity leave). Saraceno and Keck (2008) propose a different approach where social policies are categorized along a continuum from familialisation to defamilialisation. While familialisation refers to a situation where responsibility to provide care and financial support is assigned to the family, defamilialisation refers to situations where financial and care needs are satisfied through public provision. In order to do so, Keck, Hessel, and Saraceno (2009) have collected indicators on country policies regarding upward and downward support and obligations, as well as between financial and care obligations. The outcome of this collection is the Multilinks database, which contains information on four main domains: 1) responsibility for caring for children 2) responsibility for providing support for children 3) responsibility for caring for frail older people 4) responsibility for providing financial support for older people. The database is consequently the only collection of consistent and comparable measures of intergenerational support established through existing policies. Figure 1 (Keck, Hessel, and Saraceno 2009: 38) reports the percentage of time covered by leave (compensated at the level of the average wage) and covered by childcare services (for children under the age of 3 years). By adding the two measures we obtain an estimate of the 'void' left to family resources. Countries are ordered in ascending order according to the burden left to families (the "gap" bar in the figure). The bars for the six countries (Bulgaria, France, Georgia, Germany, Hungary, The Netherlands, and Russia) on which this paper focuses are bolded to highlight their position relative to the rest of Europe. 


\section{Figure 1: Division of childcare responsibilities between supported familisation, and defamilisation, EU 2003-2007}

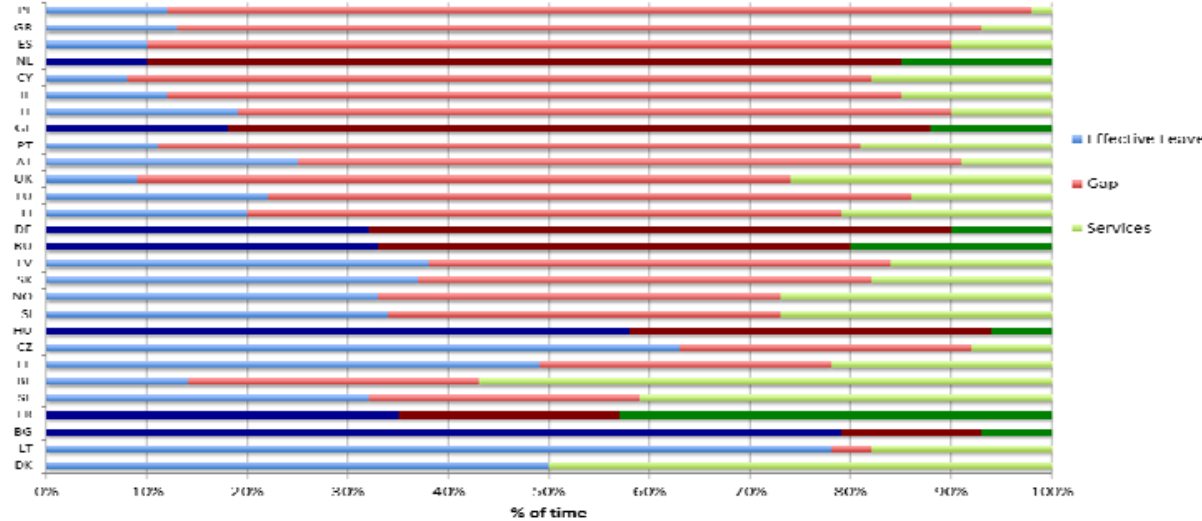

Source: Saraceno and Keck (2008) and Multilinks database for Georgia.Note: effective leave is calculated as the number of weeks paid at the average level; service coverage is calculated as the number of weeks per child available on the total number of children 0-2. Denmark is the only country in which there is even an overlap between childcare service provision and effective leave time.

Figure 1 provides important insights. There is high heterogeneity across countries in terms of offered services, leave policies, and the burden left to families. Moreover, there are no clear patterns of clustering that are consistent with the traditional EspingAndersen typology: countries in the same Esping-Andersen clusters display quite different patterns in terms of intergenerational support policies. France and Germany are a good example. Both are classified as corporatist by Esping-Andersen (1990), with high levels of state support where family benefits are based on patriarchal principles. However, the way the countries allocate funds to family policies is different (Salles, Rossier and Brachet 2010). France's policy favours the reconciliation of work and family by promoting mothers' participation in the labour force. At the same time French family policy also favours childcare by the mother, especially by offering three years parental leave and an allowance to all stay-at-home parents for a period of three years. Germany, by contrast, grants up to three years leave per child (even to mothers who were not previously working). The public childcare coverage for children under three years of age is poor and kindergartens for children aged 3-6 are often only part-time. The Netherlands, which is usually grouped together with the Nordic countries (i.e., generous support system), is placed to the far right in Figure 1, close to Mediterranean countries. Another important insight from Figure 1 is that similar levels of coverage may be reached in different ways, ranging from full supported familisation to 
defamilisation. In countries where coverage is almost exclusively supported through leave the gendered division of childcare is reinforced, as women are not encouraged to return to the labour market after maternity leave.

Finally, it is worth discussing the Eastern European countries. Before the 1990s the state provided limited, although uniform, support to families, mainly in the form of maternity leave, child allowances, and childcare facilities. Access to benefits occurred through full-time employment (Teplova 2007). Most importantly, under socialism special incentives were used to encourage women to join the labour force, which included, among other things, generous childcare services (Szelewa and Polakowski 2008). The transition period has been characterized by a significant revision of these policies (Robila 2004).It appears that with the collapse of the socialist regimes governments assumed a return to the male-breadwinner model - at least judging from the gradual closure of public childcare centres and, in particular, nurseries - while at the same time cutting financial transfers (Robila 2004; Szelewa and Polakowski 2008). However, the changes taking place during the transition period were certainly not uniform across these countries. Szelewa and Polakowski (2008) document large differences across the Eastern European countries in the development of childcare policies. Importantly, changes have not been monotonic but fluctuating, making it difficult to understand whether these countries will converge to Western-style care regimes (Teplova 2007). As is evident from Figure 1, the post-communist countries included in this analysis (Bulgaria, Georgia, Hungary, and Russia) do not appear to be very similar for what concerns the provision of childrearing for children less than three years of age. In Bulgaria care for children is almost exclusively supported by leave, while they are less generous in Hungary, though still substantial compared to Russia and Georgia.

\subsection{Preferences for grandparenting}

As we have already noted, in studying the relationship between informal childcare provided by grandparents and female labour supply the country context is not only relevant because of the different policies existing in different countries. Countries also differ in the prevalence of preferences towards providing informal childcare. These preferences are both influenced by policies and influence them in the long run. In this paper we do not aim to disentangle the link between policies and preferences, but we discuss how different context might have an impact on the estimated effect of grandparenting.

Some grandparents may have traditional value orientations and therefore show a high willingness to help out in childcare. Others might be of the opinion that this is 
mainly a task for the state, in which case they might be less keen to provide childcare (Guzman 1999). Whereas country characteristics matter for the average preferences it is important to bear in mind that within countries individual preferences may differ substantially. Importantly, if provision of grandparenting depends on preferences, then it is not unreasonable to assume that these very preferences correlate with preferences towards mothers working. Whereas such preferences will depend on observed characteristics (i.e., very old grandparents will be less willing to provide childcare), they also depend on unobserved factors. The important point here is that these unobserved preferences of the grandparents might influence the mothers' labour supply decisions. In so far as the childcare decision is the outcome of a negotiation process between the two generations, these preferences will matter for the employment decision of the mother.

In the language of econometrics, grandparents' preferences for undertaking childcare are endogenous with respect to the mother's decision to work. However the endogeneity problem is more complex than in most economic applications, simply because the outcome of interest is defined through the middle generation (i.e., the labour supply decision of the adult children); whereas the endogenous variable, childcare, is defined through the grandparents' actions (i.e., the parents of the middle generation). In the wake of these arguments the key issue is that it is necessary to control for the potential bias that arises from not observing such preferences. Against the backdrop of these arguments it is useful to characterize some family types, as follows:

Modern families (modern woman with modern parents): characterised by highly motivated working women; weak family ties; working grandmothers (or holding a positive preference towards women's employment); preference for formal childcare.

Traditional families (traditional woman with traditional parents): characterised by negative preferences for women working; strong family ties; preferences for family childcare and against formal childcare.

Mixed families (modern woman with traditional parents): characterised by women highly motivated to work; grandmothers available to help because they belong to a generation with low participation rates; mismatch across generations.

This is of course a rough and non-exhaustive classification of families, but nevertheless serves as a frame for understanding the possible direction of the bias driven by unobserved preferences. Figure 2 shows how preferences are associated with grandparental childcare $(\mathrm{H})$ and mother's labour market participation (W). In modern 
types of families, preferences positively affect the probability of working and negatively the probability of receiving help. Within these families both the mother and the grandmother tend to have positive preferences toward female work and women are not necessarily expected to stay at home caring for children.

Figure 2: Unobserved preferences and biasing effects of different types of families

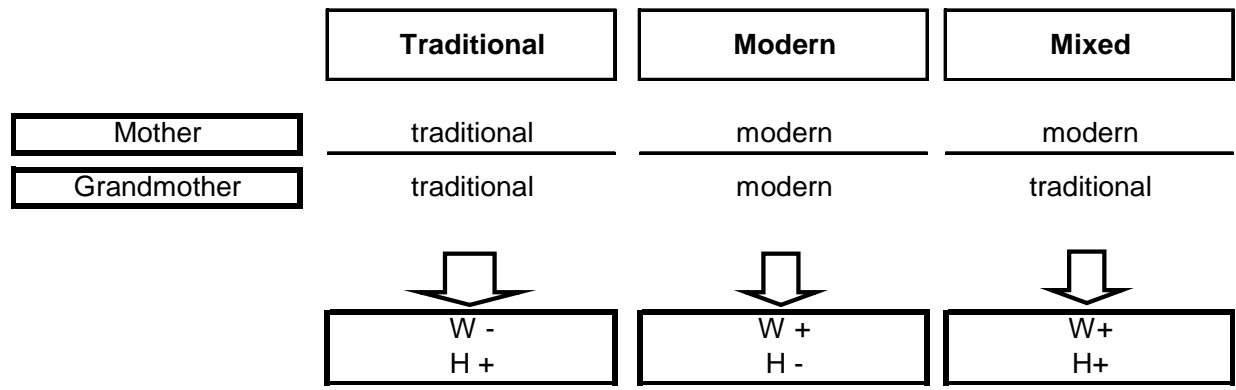

Moreover, it is likely that the grandmother prefers to invest her time working or doing activities other than taking care of grandchildren. Modern women might also prefer formal to family childcare. Not controlling for this unobserved feature underestimates (i.e., generates a negative bias) the effect of grandparents providing childcare. Conversely, in more traditional families the probability that a woman participates in the labour market is lower and family ties are stronger. This implies a higher probability of helping each other. However, in traditional families women have very strong family value orientations, and this might even decrease the probability of receiving childcare help because the mother might prefer to be the primary child carer. In this sense, she does not need childcare support from grandparents. Also, for this family type, unobserved characteristics may create a downward bias if not controlled for. A third scenario is characterized by the potential mismatch in preferences between generations. An example would be modern women (with high probability to work because of modern preferences) with traditional mothers (that are expected to be willing to provide childcare because of strong family ties and family value orientations characterising their generation). In this case the bias is positive, and not controlling for this unobserved feature overestimates the effect of grandparents providing childcare. 
The overall direction of the bias in each country will depend on the share of families of the three types outlined above. If a country is characterised by a prevalence of consistent preferences across generations (modern or traditional families) the bias is negative. On the other hand, if there is a considerable share of "mixed" families then the bias is expected to be positive. This situation is more likely to happen in countries that have experienced strong economic and structural changes over recent decades, in the sense that such changes have created a mismatch in preferences across generations.

\section{Empirical strategy}

\subsection{Data}

Our study is primarily based on individual level data taken from the Generations and Gender Survey (GGS). The GGS is a set of comparative surveys that deals with topics related to children and childbearing, partners, parents, work, and everyday life. A major innovation of the survey lies in its focus on the impact of intergenerational and gender relations on demographic behaviours. Like the Survey of Health, Ageing and Retirement in Europe (SHARE), the GGS survey includes several questions concerning relations between generations. These include frequency of contact, monetary and emotional support, and, importantly for this paper, transfers in the form of time spent on childcare. However, unlike in the SHARE data, information about intergenerational transfers is collected from the middle generation (i.e., the adult children). This means that we have extensive information about the adult children, including their sociodemographic characteristics and employment patterns. At the same time the GSS contains information on the grandparents including their demographic characteristics. It is therefore easy to model the labour supply decision (i.e., of the adult children) as a function of the availability of grandparents' childcare (Vikat et al. 2007).

Our analyses focus on seven countries: Bulgaria, France, Georgia, Germany, Hungary, the Netherlands, and Russia. Given the (cultural and institutional) differences between East and West Germany, we restrict our attention to West Germany. Sample size issues have prevented a separate analysis of East Germany, since it only accounts for $22.5 \%$ of the overall sample. Table 1 reports the number of respondents and their age range, year of data collection, and response rates for GGS data, by country. 
Table 1: Basic information on GGS surveys by country

\begin{tabular}{lllll}
\hline Country & $\begin{array}{l}\mathbf{N}^{\circ} \text { of } \\
\text { respondents }\end{array}$ & Age range & $\begin{array}{l}\text { Year of data } \\
\text { collection }\end{array}$ & Response rate \\
\hline Bulgaria & 12,914 & $18-79$ & $2004-2005$ & $78.2 \%$ \\
France & 10,079 & $18-79$ & 2005 & $71.7 \%$ \\
Georgia & 10,000 & $18-19$ & 2006 & $78.2 \%$ \\
Germany & 10,017 & $18-79$ & 2005 & $55.4 \%$ \\
Hungary & 13,540 & $20-79$ & $2001-2002$ & $\mathrm{NA}$ \\
Netherlands & 9,765 & $18-79$ & $2002-2004$ & $44.6 \%$ \\
Russia & 11,261 & $18-79$ & 2004 & $49.7 \%$ \\
\hline
\end{tabular}

Note: The data above has been provided by NIDI for all countries but for Hungary. The number of respondents and age range for Hungary are based on own calculations on the data and the year of data collection has been retrieved through the GGP website

In order to investigate the association between mothers' labour market participation and grand parenting, we restrict the analysed sample to women of working age (aged 20-55) with at least one child in the age range 0-14. In addition, we only include women who at the time of interview are married or living in a cohabiting union. We therefore exclude single mothers because they are a quite different sub-group. The proportion of single mothers is in any case very low in most of our national samples. This way, we restrict our analyses to a relatively homogenous group of women who, in particular, have similar family structures. In the analyses we only include those women who are coded as respondents in the survey, i.e., we do not consider those women who are recorded as partners. This is imposed by the fact that we do not hold information on the woman's parents when she is recorded as a partner rather than a respondent. In this way we restrict our analysis to a relatively homogenous group of women who, in particular, have similar family structures. The dependent variable of our analyses is a binary indicator taking the value one if the woman declares to be part of the labour force at the time of the interview and zero otherwise. The state of being employed encompasses those recorded to be employed, self-employed, or helping a family member with a business or a farm.

Careful attention was required when considering women currently on maternity and childcare leave. These women could be included in both the working and nonworking categories, depending on the criteria adopted for classification. Due to data limitations in some countries we were not able to retrieve the exact timing of the interview and consequently to determine for how long the mother had been on maternity/childcare leave at the time of the interview. Given these limitations the 
following strategy was adopted. Those women whose children were under the age of one and who, at the time of the interview, were recorded as being on maternity leave were dropped from the sample. The argument here is that this is a period where most mothers have an institutional and universal right-of-leave period in which the mother is the necessarily primary carer of the child. Whereas grandparents undoubtedly play an important support role in this period, it is less clear how their help has an impact on mothers' decision to work. Unfortunately we were not able to discern the women who were in a 'hybrid' period, who ended the maternity period after roughly four months with $100 \%$ of their previous salary and whose child was still under the age of one year. We chose a common threshold of one year (related to the child's age), due to the data limitations discussed above. Conversely, those women whose child was aged one and above and who declared themselves to be on childcare leave were included in the "nonworking" category. The reason is that these women are choosing not to re-enter the labour force and to stay home caring for children. This strategy was adopted for all countries except the Netherlands, where information as to whether the woman is on maternity/childcare leave is not available. We acknowledge the fact that this strategy entails limitations and is a tentative classification at best. We tried alternative categorisations and qualitatively the results are stable, and hence robust.

The covariates included in the models can be divided into four groups: education, household structure, intergenerational links, and extended family characteristics. Education and family structure are mainly used as controls in the models, while intergenerational links and extended family characteristics are the main variables of interest. Education is defined by three dummy variables representing the levels of education. They are constructed in the same way for all countries and based on the ISCED code (primary/lower secondary education, upper secondary/post-secondary education, and tertiary). In the regression analyses the baseline category corresponds to primary and lower secondary educational level. "Household Structure" is controlled for through a set of dummy variables reflecting whether the respondent has children in the following age categories: 0-4, 5-10, 11-14. "Intergenerational Links" is our key independent variable and it measures the childcare provided by grandparents. The variable takes the value one when the respondent receives regular help with childcare from her parents, or more precisely from at least one of them (i.e., either the mother or father). We identify mothers receiving regular grandchild care through the following question: "Do you get regular help with childcare from relatives or friends or other people for whom caring for children is not a job?" If the answer is "yes" the respondent was then asked: "From whom do you get this help?" for which "grandparents" is one of the possible options. One issue here is that we do not know if the mother also receives help from the grandparents-in-law, which may affect estimation. First, if there is no correlation between help received from grandparents and grandparents-in-law, there 
will not be any bias. Second, if there is a negative correlation, then this will generate a further downward bias, making our estimates conservative. If instead there is a positive correlation, which will mean that there is increased grandparent help from grandparents-in-law, there will be an upward bias. This is of course possible and will happen if the adult children in the couple both have strong family ties. In this case, our estimates would refer to the joint impact of the grandparenting of both sets of grandparents. Finally, by "Extended Family Characteristics" we mean whether the respondent's mother is alive and the number of siblings the respondent has. These are used as instrumental variables when implementing the simultaneous equations approach, as explained in the next section.

\subsection{Methodology}

The outcome of our interest is a binary variable, which indicates the participation in the labour market ( $W=1$ if the mother works and 0 otherwise). We can model the underlying unobserved propensity to work $W^{*}$ as a function of a set of covariates $X^{w}$ and the childcare help received from grandparents $(H$, a dummy variable taking value 1 if woman receives childcare help from her parents and 0 otherwise):

$$
W^{*}=X^{W} \beta^{W}+\delta H+\varepsilon^{W}
$$

with $\varepsilon^{\mathrm{w}} \sim \mathrm{N}(0,1)$. The appropriateness of the simple probit approach described above relies on the assumption of selection on observables: in order to guarantee that $\delta$ consistently estimates the effect of grandparents' childcare help $(H)$, we have to rule out the possibility that unobservable characteristics influence both $H$ and $W$. However, as explained in section 2.2, there are several reasons to believe that childcare help received from grandparents is endogenous to the woman's labour supply decision. The preferences of the mother and her parents toward childcare and work are unobserved, and this implies a correlation between the error term $\varepsilon^{w}$ and the variable of interest $H$, and ultimately that $\delta$ is biased. Instrumental Variable (IV) methods are very popular techniques in econometrics dealing with endogeneity issues (Greene 1997). Instruments, $Z$, are variables associated with the endogenous variable $(H)$ and are supposed to influence the outcome $(W)$ only through the effect on the grandparents' help. That is, they should not have a direct effect on the outcome. We implement the IV approach using a bivariate probit model estimated by Full Information Maximum Likelihood (FIML), as implemented by the biprobit command in STATA (see e.g., Maddala 1983; Hardin 1996; Greene 1997). Model (1) will therefore be estimated 
together with a second probit model where the outcome is the probability of receiving help from grandparents.

The propensity to receive help $\left(H^{*}\right)$ depends on a set of covariates $X^{H}$, which may (or may not) coincide with those affecting the decision to work. Since we want to identify the impact of actually receiving grandparents' childcare help on women's labour supply, rather than the impact of the propensity to receive grandparents' childcare, we adopt the type II specification in the terminology of Blundell and Smith (1993). That is, we adopt a recursive model in which grandparents' childcare is assumed to influence the probability that a woman works:

$$
\left\{\begin{array}{l}
W^{*}=X^{W} \beta^{W}+\delta H+\varepsilon^{W} \\
H^{*}=X^{H} \beta^{H}+\varepsilon^{H}
\end{array}\right.
$$

The error terms of the two equations are allowed to be freely correlated in order to account for the possibility that some unobserved factors influence both the decisions to work and to receive grandparents' help ${ }^{4}$. In our case preferences might cause this correlation to be different from zero. If this is the case it means that there is endogeneity and the bivariate probit model has to be used in order to get unbiased estimates. The sign of the correlation gives the direction of the bias in the naive probit model.

To improve identification (Wilde 2000) we use two instruments for the probability that the mother received help in caring for her children: $Z_{I}$ (a dummy variable taking value 1 if the woman's mother is alive at the time of the interview and 0 otherwise) and $Z_{2}$ (number of siblings the woman has). The variables $Z_{1}$ and $Z_{2}$ are included in the set of covariates $X^{H}$ but not in $X^{W}$. Both variables can be a priori considered good instruments since they are expected to be associated with grandparenting (instruments are relevant) but not with the labour supply decision (after grandparents' childcare and covariates are controlled for) (instruments are valid). In particular, $Z_{l}$ is expected to be positively (and strongly) correlated with $H$. This argument is strongly supported by many studies, whereby it is indicated that grandmothers, as opposed to grandfathers, are the primary source of supply of childcare (Tobio 2001). Moreover, after controlling for age effects, the mother being alive should not produce direct effects on the decision to participate in the labour market. As for $Z_{2}$, we expect that having more siblings reduces the likelihood of receiving childcare help from grandparents, because a higher number of siblings implies a potentially higher number of nephews and nieces. Again, we do not expect direct effects on participation in the labour market. However, the number of

\footnotetext{
${ }^{4}$ More precisely, in the bivariate probit model the error terms in the two equations follow a bivariate normal distribution. Each error has zero mean and a variance equal to 1 .
} 
siblings could influence the distance between mothers and their parents (Konrad et al. 2002). Similarly, bad health conditions of grandparents can have an impact on the mother's working status if she has to provide care to the elderly. To address these problems and evaluate the quality of the instruments we use the functional form as identifying restrictions. First, we test the null hypothesis of insignificance of the instruments in the participation equation (test for validity) and then we test the null hypothesis of insignificance of the instruments in the help received (test for relevance). Secondly, we conduct a robustness analysis where mothers providing care to their parents have been excluded. The results are similar to those presented below.

\section{Results}

We start discussing the empirical results by first showing some descriptive statistics on labour force participation and grandparents' childcare by country, presented in Table 2 . It shows female participation rates for the sub-sample used in our estimation. It also provides country-level estimates of female participation rates as provided by Eurostat. Finally, the last row reports the percentage of female respondents who declare that they receive regular help with childcare from their parents, by working status.

Table 2: Descriptive statistics by country: participation rates and percentage of women receiving grandparents' childcare by working status.

\begin{tabular}{|c|c|c|c|c|c|c|c|c|c|c|c|c|c|c|}
\hline & \multicolumn{2}{|c|}{ Bulgaria } & \multicolumn{2}{|l|}{ France } & \multicolumn{2}{|c|}{ Georgia } & \multicolumn{2}{|c|}{ Germany } & \multicolumn{2}{|c|}{ Hungary } & \multicolumn{2}{|c|}{ Netherlands } & \multicolumn{2}{|c|}{ Russia } \\
\hline & Work & No & Work & No & Work & No & Work & No & Wrk & No & Work & No & Work & No \\
\hline $\begin{array}{l}\text { Participation rate } \\
\text { sub-sample* }\end{array}$ & $61.7 \%$ & & $70.9 \%$ & & $29.7 \%$ & & $53.7 \%$ & & $56.6 \%$ & & $61.5 \%$ & & $65.4 \%$ & \\
\hline $\begin{array}{l}\text { Female } \\
\text { employment rate } \\
\star \star\end{array}$ & $51.7 \%$ & & $58.4 \%$ & & $50.1 \%$ & & $59.6 \%$ & & $51 \%$ & & $66.4 \%$ & & $54.4 \%$ & \\
\hline $\begin{array}{l}\text { Grandparents } \\
\text { provide childcare } \\
\text { help }\end{array}$ & $22.1 \%$ & $19.4 \%$ & $28.1 \%$ & $17.2 \%$ & $7.6 \%$ & $5.8 \%$ & $16.8 \%$ & $12.5 \%$ & $43.1 \%$ & $43.7 \%$ & $64.6 \%$ & $58.2 \%$ & $26.9 \%$ & $26.0 \%$ \\
\hline $\begin{array}{l}\text { Number of } \\
\text { observations }\end{array}$ & 1738 & & 1100 & & 1293 & & 809 & & 1370 & & 1143 & & 745 & \\
\hline
\end{tabular}

*Own calculations based on our sub-sample of analysis (Women aged 20-55, married and with at least one child aged 0-14).

** Female participation rates at country level. Country level employment rates for Bulgaria, France, Germany, Hungary and the Netherlands are takenfrom EUROSTAT (last date accessed: February 2012). Country level participation rates for Georgia and Russia are taken from the UN statistical database. 
The heterogeneity in participation rates across countries is remarkable, both when looking at aggregate country figures and when looking at participation rates for the subsample. In some of the countries, specifically in Bulgaria, France, Russia, and Hungary, the sub-sample of women we consider exhibits higher participation rates than the entire population. We have to bear in mind that we are looking at a subsample of mothers that might have different characteristics to the rest of the population. For example, in some countries age at first child is high. Therefore our selection excludes very young women that do not participate in the labour force. We also exclude old women that might have lower participation rates than younger generations. The reverse occurs in Georgia (where the difference between the participation rate of our sub-sample and the population level estimate is quite marked) and to a minor extent in the Netherlands and in Germany. The Georgia statistics suggest that the country is still anchored to a traditional system where mothers are expected to stay at home caring for children. Participation rates for the sub-sample are particularly high in Bulgaria, France, and Russia. In contrast, Germany, the Netherlands, and Hungary show medium levels of mothers' participation, while Georgia is the only country where less than half of the sub-sample was working at the time of interview. As expected, working mothers receive childcare more frequently than non-working women, with the exception of Georgia and Hungary where the percentages almost coincide. Use of grandparents' childcare is particularly high in the Netherlands and Hungary. In line with the fact that the majority of mothers in Georgia are not part of the labour force, the level of childcare help received from grandparents is also the lowest across the countries analysed.

Table 3 presents estimates obtained from a naive probit model. From this table we can see that the association between mother's labour supply and childcare help received from grandparents is positive and significant in France, Georgia, Germany, Hungary, and the Netherlands. The association is instead positive and not significant in Bulgaria and Russia. The results for the estimated coefficients of control variables are as expected. In particular, highly educated women are more likely to work with respect to the reference category with the lowest educational levels. Moreover, having a child aged between 0 and 4 is negatively associated with the probability of working, whereas the educational level of the father has no significant effect. 
Table 3: Marginal effect on probability of working (married women with at least one child 0-14 aged 20-55)

\begin{tabular}{|c|c|c|c|c|c|c|c|}
\hline & Bulgaria & France & Georgia & Germany & Hungary & Netherlands & Russia \\
\hline \multirow[t]{2}{*}{ Woman Age } & $0.083^{\star \star \star}$ & $0.076^{\star \star \star}$ & $0.056^{\star \star \star}$ & $0.074^{\star \star}$ & $0.081^{\star \star \star}$ & $0.046^{*}$ & $0.071^{\star \star \star}$ \\
\hline & $(0.021)$ & $(0.019)$ & $(0.018)$ & $(0.029)$ & $(0.023)$ & $(0.026)$ & $(0.026)$ \\
\hline \multirow[t]{2}{*}{ Woman Age ${ }^{\wedge} 2$} & $-0.001^{\star \star \star}$ & $-0.001^{\star \star \star}$ & $-0.001^{\star \star}$ & $-0.001^{\star \star}$ & $-0.001^{\star \star \star}$ & -0.001 & $-0.001^{\star \star}$ \\
\hline & $(0.000)$ & $(0.000)$ & $(0.000)$ & $(0.000)$ & $(0.000)$ & $(0.000)$ & $(0.000)$ \\
\hline \multirow[t]{2}{*}{$\begin{array}{l}\text { Woman Education } \\
\text { Medium }\end{array}$} & $0.472^{\star \star \star}$ & $0.111^{\star \star \star}$ & 0.043 & $0.173^{\star \star \star}$ & $0.221^{\star *}$ & $0.212^{\star \star \star}$ & 0.004 \\
\hline & $(0.076)$ & $(0.037)$ & $(0.057)$ & $(0.060)$ & $(0.112)$ & $(0.038)$ & $(0.059)$ \\
\hline \multirow[t]{2}{*}{$\begin{array}{l}\text { Woman Education } \\
\text { High }\end{array}$} & $0.552^{\star \star \star}$ & $0.280^{\star \star \star}$ & $0.216^{\star \star \star}$ & $0.227^{\star \star \star}$ & $0.476^{\star \star \star}$ & $0.278^{\star \star \star}$ & 0.052 \\
\hline & $(0.047)$ & $(0.038)$ & $(0.068)$ & $(0.066)$ & $(0.094)$ & $(0.043)$ & $(0.066)$ \\
\hline \multirow[t]{2}{*}{$\begin{array}{l}\text { Man Education } \\
\text { Medium }\end{array}$} & 0.080 & 0.023 & 0.024 & -0.020 & 0.206 & -0.027 & -0.031 \\
\hline & $(0.096)$ & $(0.038)$ & $(0.066)$ & $(0.081)$ & $(0.130)$ & $(0.037)$ & $(0.046)$ \\
\hline \multirow[t]{2}{*}{ Man Education High } & 0.100 & $-0.080^{\star}$ & 0.009 & -0.021 & $0.353^{\star \star \star}$ & 0.019 & 0.023 \\
\hline & $(0.094)$ & $(0.048)$ & $(0.071)$ & $(0.087)$ & $(0.128)$ & $(0.056)$ & $(0.056)$ \\
\hline \multirow[t]{2}{*}{ Children aged 0-4 } & $-0.295^{\star \star \star}$ & $-0.180^{\star \star \star}$ & $-0.168^{\star \star \star}$ & $-0.284^{\star \star \star}$ & $-0.457^{\star \star \star}$ & $-0.123^{\star \star \star}$ & $-0.315^{\star \star \star}$ \\
\hline & $(0.036)$ & $(0.037)$ & $(0.033)$ & $(0.047)$ & $(0.035)$ & $(0.042)$ & $(0.051)$ \\
\hline \multirow[t]{2}{*}{ Child aged 5-10 } & $-0.078^{\star \star}$ & $-0.088^{\star \star \star}$ & -0.030 & $-0.072^{\star}$ & $-0.111^{\star \star \star}$ & $-0.156^{\star \star \star}$ & -0.039 \\
\hline & $(0.032)$ & $(0.031)$ & $(0.031)$ & $(0.043)$ & $(0.035)$ & (0.033) & $(0.049)$ \\
\hline \multirow[t]{2}{*}{ Child aged 11-14 } & $-0.061^{*}$ & $-0.101^{\star \star \star}$ & -0.031 & $0.079^{\star}$ & $-0.086^{\star \star}$ & $-0.079^{*}$ & $-0.125^{\star \star}$ \\
\hline & $(0.036)$ & $(0.038)$ & $(0.033)$ & $(0.048)$ & $(0.040)$ & $(0.042)$ & $(0.056)$ \\
\hline \multirow[t]{2}{*}{$\begin{array}{l}\text { Grandparents' } \\
\text { childcare }\end{array}$} & 0.024 & $0.099^{\star \star \star}$ & $0.161^{\star \star}$ & $0.146^{\star \star \star}$ & $0.057^{\star}$ & $0.065^{\star}$ & 0.061 \\
\hline & $(0.031)$ & $(0.031)$ & $(0.063)$ & $(0.050)$ & $(0.031)$ & $(0.033)$ & $(0.041)$ \\
\hline $\begin{array}{l}\text { Number of } \\
\text { observations }\end{array}$ & 1.738 & 1.100 & 1.293 & 809 & 1.370 & 1.143 & 745 \\
\hline
\end{tabular}

Note: ${ }^{\star \star \star} p<0.01,{ }^{\star \star} p<0.05,{ }^{*} p<0.1$ 
Table 4 reports the full set of estimates from the bivariate probit model. The full estimates are of interest not only because they correct for the endogeneity of grandparents' childcare provision when estimating mothers' labour supply, but also because they inform us about the drivers behind grandparents' childcare. We find that in almost all countries mothers' characteristics matter for labour supply. Somewhat surprisingly, we find that mothers' characteristics do not have a huge impact on whether they receive childcare from grandparents. For France we find that grandparents tend to help more when women have higher education, and that the age of the children matters for other countries. Reassuringly, the associations between the instruments and grandparents' help are highly significant, confirming their relevance.

Table 4: Marginal effects estimated with bivariate probit models (standard errors in parenthesis)

\begin{tabular}{lccccccc}
\hline & Bulgaria & France & Georgia & Germany & Hungary & Netherlands & Russia \\
\hline Woman Age & $0.073^{\star \star \star}$ & $0.074^{\star \star \star}$ & $0.052^{\star \star \star}$ & $0.069^{\star \star}$ & $0.067^{\star \star \star}$ & $0.049^{\star}$ & $0.070^{\star \star \star}$ \\
& $(0.021)$ & $(0.020)$ & $(0.020)$ & $(0.030)$ & $(0.024)$ & $(0.028)$ & $(0.026)$ \\
Woman Age^2 & $-0.001^{\star \star \star}$ & $-0.001^{\star \star \star}$ & $-0.001^{\star \star}$ & $-0.001^{\star \star}$ & $-0.001^{\star \star}$ & -0.001 & $-0.001^{\star \star}$ \\
& $(0.000)$ & $(0.000)$ & $(0.000)$ & $(0.000)$ & $(0.000)$ & $(0.000)$ & $(0.000)$ \\
Woman Education Medium & $0.432^{\star \star \star}$ & $0.100^{\star \star}$ & 0.045 & $0.138^{\star \star}$ & $0.201^{\star}$ & $0.213^{\star \star \star}$ & 0.009 \\
Woman Education High & $(0.080)$ & $(0.042)$ & $(0.057)$ & $(0.067)$ & $(0.116)$ & $(0.038)$ & $(0.059)$ \\
& $0.507^{\star \star \star}$ & $0.266^{\star \star \star}$ & $0.220^{\star \star \star}$ & $0.192^{\star \star}$ & $0.410^{\star \star \star}$ & $0.278^{\star \star \star}$ & 0.054 \\
Man Education Medium & $(0.059)$ & $(0.045)$ & $(0.068)$ & $(0.075)$ & $(0.110)$ & $(0.043)$ & $(0.065)$ \\
& 0.067 & 0.016 & 0.028 & -0.026 & 0.157 & -0.026 & -0.026 \\
Man Education High & $(0.096)$ & $(0.040)$ & $(0.066)$ & $(0.079)$ & $(0.138)$ & $(0.037)$ & $(0.046)$ \\
& 0.074 & -0.076 & 0.016 & -0.036 & $0.291^{\star \star}$ & 0.022 & 0.028 \\
Children aged 0-4 & $(0.097)$ & $(0.048)$ & $(0.072)$ & $(0.086)$ & $(0.138)$ & $(0.056)$ & $(0.056)$ \\
& $-0.288^{\star \star \star}$ & $-0.176^{\star \star \star}$ & $-0.163^{\star \star \star}$ & $-0.276^{\star \star \star}$ & $-0.460^{\star \star \star}$ & $-0.120^{\star \star \star}$ & $-0.319^{\star \star \star}$ \\
Child aged 5-10 & $(0.037)$ & $(0.038)$ & $(0.034)$ & $(0.050)$ & $(0.035)$ & $(0.043)$ & $(0.051)$ \\
Child aged 11-14 & $-0.089^{\star \star \star}$ & $-0.087^{\star \star \star}$ & -0.034 & $-0.071^{\star}$ & $-0.118^{\star \star \star}$ & $-0.156^{\star \star \star}$ & -0.052 \\
Grandparents' childcare & $(0.031)$ & $(0.031)$ & $(0.032)$ & $(0.042)$ & $(0.034)$ & $(0.033)$ & $(0.051)$ \\
& -0.041 & $-0.096^{\star \star}$ & -0.037 & $0.109^{\star \star}$ & $-0.070^{\star}$ & $-0.082^{\star}$ & $-0.153^{\star \star}$ \\
& $(0.037)$ & $(0.038)$ & $(0.034)$ & $(0.050)$ & $(0.040)$ & $(0.043)$ & $(0.063)$ \\
& $0.312^{\star \star \star}$ & 0.173 & -0.048 & $0.420^{\star \star \star}$ & $0.325^{\star \star \star}$ & 0.040 & -0.088 \\
& $(0.094)$ & $(0.110)$ & $(0.244)$ & $(0.139)$ & $(0.097)$ & $(0.086)$ & $(0.174)$ \\
\hline
\end{tabular}


Table 4: (Continued)

\begin{tabular}{|c|c|c|c|c|c|c|c|}
\hline & Bulgaria & France & Georgia & Germany & Hungary & Netherlands & Russia \\
\hline \multirow[t]{2}{*}{ Woman Age } & 0.022 & $0.036^{\star}$ & -0.009 & 0.006 & $0.052^{\star \star}$ & $0.134^{\star \star \star}$ & 0.004 \\
\hline & $(0.017)$ & $(0.02)$ & $(0.02)$ & $(0.02)$ & $(0.024)$ & $(0.029)$ & $(0.025)$ \\
\hline \multirow[t]{2}{*}{ Woman Age^2 } & $-0.000^{*}$ & $-0.001^{\star \star}$ & 0.000 & 0.000 & $-0.001^{\star \star \star}$ & $-0.002^{\star \star \star}$ & 0.000 \\
\hline & $(0.000)$ & $(0.000)$ & $(0.000)$ & $(0.000)$ & $(0.000)$ & $(0.000)$ & $(0.000)$ \\
\hline \multirow[t]{2}{*}{ Woman Education Medium } & 0.077 & $0.113^{\star \star}$ & -0.002 & 0.062 & $0.433^{\star \star}$ & 0.054 & 0.017 \\
\hline & $(0.07)$ & $(0.044)$ & $(0.044)$ & $(0.04)$ & $(0.172)$ & $(0.041)$ & $(0.049)$ \\
\hline \multirow[t]{2}{*}{ Woman Education High } & 0.136 & $0.152^{\star \star \star}$ & 0.007 & 0.067 & $0.416^{\star \star \star}$ & -0.053 & -0.015 \\
\hline & $(0.093)$ & $(0.05)$ & $(0.05)$ & $(0.06)$ & $(0.103)$ & $(0.078)$ & $(0.055)$ \\
\hline \multirow[t]{2}{*}{ Man Education Medium } & 0.066 & $0.069^{\star}$ & 0.007 & -0.002 & 0.135 & 0.046 & 0.016 \\
\hline & $(0.071)$ & $(0.037)$ & $(0.037)$ & $(0.056)$ & $(0.183)$ & $(0.041)$ & $(0.039)$ \\
\hline \multirow[t]{2}{*}{ Man Education High } & 0.108 & -0.053 & 0.01 & 0.013 & 0.12 & 0.084 & 0.008 \\
\hline & $(0.105)$ & $(0.041)$ & $(0.041)$ & $(0.06)$ & $(0.159)$ & $(0.059)$ & $(0.047)$ \\
\hline \multirow[t]{2}{*}{ Children aged 0-4 } & 0.037 & -0.038 & 0.01 & 0.027 & $0.126^{\star \star \star}$ & $0.146^{\star \star \star}$ & -0.026 \\
\hline & $(0.027)$ & $(0.033)$ & $(0.033)$ & $(0.033)$ & $(0.038)$ & $(0.045)$ & $(0.045)$ \\
\hline \multirow[t]{2}{*}{ Child aged 5-10 } & $0.048^{\star \star}$ & 0.011 & -0.015 & 0.013 & $0.059^{\star}$ & 0.003 & $-0.073^{\star}$ \\
\hline & $(0.023)$ & $(0.03)$ & $(0.03)$ & $(0.028)$ & $(0.034)$ & $(0.039)$ & $(0.044)$ \\
\hline \multirow[t]{2}{*}{ Child aged $11-14$} & -0.032 & -0.031 & $-0.030^{\star \star}$ & $-0.076^{\star \star}$ & -0.038 & $-0.086^{*}$ & $-0.161^{\star \star \star}$ \\
\hline & $(0.025)$ & $(0.033)$ & $(0.033)$ & $(0.03)$ & $(0.037)$ & $(0.045)$ & $(0.041)$ \\
\hline \multirow[t]{2}{*}{ Woman mother alive } & $0.134^{\star \star \star}$ & $0.192^{\star \star \star}$ & $0.050^{\star \star \star}$ & $0.092^{\star \star \star}$ & $0.307^{\star \star \star}$ & $0.519^{\star \star \star}$ & $0.276^{\star \star \star}$ \\
\hline & $(0.023)$ & $(0.027)$ & $(0.027)$ & $(0.028)$ & $(0.035)$ & $(0.042)$ & $(0.021)$ \\
\hline \multirow[t]{2}{*}{ Number of siblings } & $-0.075^{\star \star \star}$ & $-0.040^{\star \star \star}$ & $-0.018^{\star \star \star}$ & $-0.023^{\star \star}$ & $-0.039^{\star \star \star}$ & $-0.060^{\star \star \star}$ & $-0.061^{\star \star \star}$ \\
\hline & $(0.011)$ & $(0.008)$ & $(0.008)$ & $(0.009)$ & $(0.01)$ & (0.009) & (0.015) \\
\hline \multirow[t]{2}{*}{ athrho } & $-0.614^{\star \star}$ & -0.166 & 0.310 & -0.607 & $-0.516^{\star \star}$ & 0.045 & 0.268 \\
\hline & $(0.306)$ & $(0.259)$ & (0.439) & $(0.555)$ & $(0.234)$ & $(0.142)$ & $(0.301)$ \\
\hline Number of observations & 1.738 & 1.100 & 1.293 & 809 & 1.370 & 1.143 & 745 \\
\hline
\end{tabular}

Note: ${ }^{\star \star \star} p<0.01,{ }^{\star \star}{ }^{\star} p<0.05,{ }^{*} p<0.1$

Controlling for the endogeneity of grandparents' childcare provision changes the results considerably. In several countries the effect of grandparents' childcare increases once endogeneity is properly controlled for. This is the case for Bulgaria, France, Germany, and Hungary, and the change in magnitude is substantial. In other words, 
there is a negative bias in the probit estimate for these countries, as also shown by the negative sign of the estimated correlation between the error terms. Importantly, for these countries the effect of informal childcare in the bivariate probit model is statistically significant (however for France only at the 10\% level). In a second set of countries (Georgia, Russia, and the Netherlands) the bias goes in the opposite direction: controlling for endogeneity the estimated grandparents' childcare effect is reduced and loses statistical significance. For Russia the effect is also not significant in the probit model. To explain why we find different results in the two sets of countries we can refer to the discussion in section 2. Looking back at Figure 2, we could argue that the negative bias in the first set of countries is due to the prevalence of preferences toward grandparents' childcare and against mothers' participation (traditional families) or to the prevalence of preferences toward public childcare and mothers' participation (modern families). In societies with a prevalence of 'modern' preferences, grandparents might have negative (unobserved) preferences for providing childcare. Preferences for public childcare might arise because of a good supply of services. In other words, if grandparents observe that in their country public childcare services are good, they may feel less inclined to provide childcare. In modern contexts it is also likely that mothers have positive preferences toward participation in the labour market.

For Georgia, Russia, and the Netherlands there is no indication of a causal effect of informal childcare on mothers' work decisions. In fact in all these countries the effect in the bivariate probit is not significant. The positive direction of the bias according to Figure 2 might be explained by a mismatch in preferences across generations. For Georgia and Russia this might be caused by the huge economic and social transformations that have occurred in post-communist countries. Instead, France is likely to belong to the first group where both mothers and grandmothers have relatively modern preferences, and where female labour force participation is high and has been so for quite some time. The same can be said about Germany, though here high participation rates are driven by the availability of part-time jobs. The Netherlands appears to be of a more mixed type. Until recently female labour force participation was well below the European average. Between 1979 and 1997 Dutch employment as a whole grew by $28 \%$. This occurred as a consequence of the introduction of part-time jobs on a large scale and increased availability and affordability of day-care.

It is not easy to explain the results obtained in Hungary, Bulgaria, Russia, and Georgia. These countries exhibited quite high participation rates and good coverage in childcare services until the end of the 1980s. All the analysed Eastern European and Soviet countries experienced a decline in participation rates during the period 19802006, whereas in the earlier Soviet years female labour force participation was much higher than in the OECD countries. A number of reasons have been put forward to explain this phenomenon. Holding a job was both a near political obligation and an 
economic necessity since a family could not easily afford to live decently on the income from only one wage-earner, and well-developed childcare structures favoured female economic activity (Barta et al.1984; Bodrova and Anker 1985; Atkinson and Micklewright 1992). Since employment was nearly universal, the decline in participation rates coincides with the transition period following the fall of the Berlin Wall. Given the similar economic structure and labour market institutions of these countries before the transition and the common elements of the recent economic reforms, one might expect the change in women's economic status over this period to be broadly similar across Eastern European and Soviet countries. However, the opposite appears to be true.

While wages have unambiguously improved relative to men's wages in all Eastern European countries analysed, women in Russia have fared much worse in terms of relative wages since market reforms were introduced (Brainerd 2000). Moreover, in Russia family policies have been introduced that encourage women to stay at home with their children. There has been a movement from Soviet-style enterpriselevel provision of services to a more Western European, social insurance model, where the government collects social insurance or social security premiums and pays out maternity, parental, or other benefits. Yet these new systems coexist with Soviet-era enterprise provision and a hard neo-liberal private sector which sometimes offers informal contracts and no benefits at all. Informal contracts are indeed on the rise in Russia. The significance of informal agreements and their impact on female employment should not be underestimated. Given the sometimes-poor law enforcement, the actual terms being negotiated are often made directly between employers and employees. This puts many parents in a poor bargaining position, especially working women, who are still the primary users of family leave. Moreover, while the current package of family leave benefits in Bulgaria is designed to reduce the job penalties of parenthood, in Georgia and in Russia women are considered more expensive from the employers' perspective and perhaps less reliable as workforce because they have the right to take generous maternity leave.

Since mothers' need to receive help for childcare is reduced when children are older, as a robustness check we also conducted additional analyses excluding mothers who only have children older than 10 . The results (not showed here for brevity but available from authors upon request) are very similar to those reported in Tables 3 and 4. 


\section{Concluding remarks}

When studying the dynamics behind female labour force participation and fertility it becomes of utmost importance to consider the provision of intergenerational transfers, informal provision of childcare, and the institutional setting characterizing each country. Clearly, childcare is a crucial variable in this setting, since it is one of the key mechanisms to reconcile work and family. The need for childcare policies to reconcile work with family life was also recognized by the European Union, which in 2010 set the "Barcelona Summit" targets for the availability of childcare institutions to $33 \%$ for children below 3 years and $90 \%$ for children from age 3 to school age. Currently in the EU15 countries enrolment rates in childcare facilities for children below age 3 vary between 3\% (Greece) to over 60\% (Denmark), reflecting the large variety in how early childcare is organized in different countries.

The main challenge imposed by our research question is that we cannot observe how generations interact and negotiate to reach the observed labour and childcare supply. In addition, we do not observe preferences for work (of the middle generation) and preferences for childcare (of the grandparents). Whereas this represents a classic statistical problem of omitted variable bias which obviously needs to be taken care of, it also informs about the extent unobserved preferences matter in the different countries included in our analysis. The first interesting and appealing result is that the direction of the bias differs across countries: France, Germany, Hungary, and Bulgaria show strong negative biases, while Russia, Georgia, and the Netherlands display a positive but smaller bias. Receiving childcare help from grandparents has a positive and significant impact on the mother's labour supply decision in France, Germany, Bulgaria, and Hungary. These results are consistent with the papers of Dimova and Wolff (2008, 2011). However, in their comparative paper (2008) they pool data from ten countries and estimate an average effect of grandparental childcare. This might pose a weakness because, as we show in this paper, the effect of grandparental childcare varies considerably by country. Our inclusion of Bulgaria, Russia, and Georgia makes the study intriguing. These are countries which prior to the fall of the Iron Curtain had a different societal structure to western countries, and, equally important, have experienced dramatic economic and societal upheavals since1989. However, understanding how the complex intra-family dynamics function in countries that have experienced such drastic changes over the last 20 years may not be straightforward. Another important insight from our analysis is that we do not find clear patterns of country clusters. In terms of grandparenting and supply of public childcare there appears to be no direct consistency with the widely used typology of Esping-Andersen (1999). 
There are many challenges for future research. It would be of interest to perform a similar analysis using the number of hours worked, or rather the mother's choice between working full-time versus part-time or working full-time versus not working. Whereas the current analysis focuses on labour force participation, such an extension would answer the question of how the quantity of mothers' labour supply is driven by grandparents being able (and willing) to provide childcare. Distinguishing the decision to work part-time versus full-time in our analysis is challenging for several reasons, and initial estimates were difficult to compute. An ordinal probit specification of work status, estimated in conjunction with a simultaneous equation of grandparenting, did not perform well from a statistical point of view. An alternative and simpler approach that we explored consisted of implementing the same analysis on the sub-sample of working mothers. In such analysis the dependent variable in the working equation takes the value one for mothers working full-time and zero for those working part-time. The key problem here is the small percentage of mothers working part-time in some of the countries. This was as small as 6-7\% in Bulgaria and Russia, leading to nonconvergence in the optimization procedure. Moreover, from a simple probit analysis we found that the effect of grandparents' childcare on the decision to work full-time is much smaller than the effect we found on the decision to work or not. The modest effect also contributes to hampering the convergence of the bivariate model. From the probit analysis and from the bivariate probit models that achieved convergence it seems that the help received from grandparents is more important for the decision to work than for the decision of how much to work. This result, however, is highly dependent on the institutional context and merits further investigation in future work. For example, this might be due to the very scarce supply of part-time jobs (in which case mothers cannot really choose how much to work) or to the limitation of part-time jobs in particular sectors. Also the choice of the working sector where part-time jobs are more easily available might be endogenous and need accurate consideration.

Finally, a highly interesting line of research would be to consider the more diverse patterns of interdependency between family generations and between men and women giving rise to a multitude of care responsibilities. For individuals in the middle generations, especially women who relate 'up' to ageing parents and 'down' to children and grandchildren, these interdependencies are self-evident. However, in the literature on female labour force participation these complex linkages seem to be taken for granted and do not appear to have been taken seriously yet (Pagani and Marenzi 2008 constitute an exception). Transfers 'up' and 'down' family lines are rarely considered together. For instance, the dominant perspective in ageing research is on the amounts of care for frail old people provided by family members, including spouses and adult children. Yet the older generations often serve as a significant source of support and help for young families, not only by caring for young grandchildren but also through 
financial transfers and provision of practical help. However, the extent to which such intergenerational transfers are present and important clearly depends on the context considered. Whereas intergenerational transfers are critical in countries where state welfare is weak and institutional provision of services is low (e.g., Mediterranean countries) they play much less of a role in Social Democratic countries where the state provides generous support in terms of caring for the elderly and the young and where gender equality is strongly promoted. Thus, what is often termed "generational squeezes", i.e., when young grandchildren or children and parents or grandparents simultaneously are in need of help, will affect women's labour force participation in different ways. Can we expect women to refrain from working outside the home in certain contexts because of care responsibilities? To what extent does help with caring tasks from spouses, adult children, and parents better enable people to hold jobs? Whereas the literature on female labour force participation typically considers transfers upwards to ageing parents and downwards to children and grandchildren, it tends to disregard transfers received from older and younger generations and from partners.

\section{Acknowledgements}

This paper was written in the context of MULTILINKS (How Demographic Changes Shape Intergenerational Solidarity, Well-being, and Social Integration), a programme of research funded through the seventh framework programme of the European Commission (grant number217523). Arnstein Aassve gratefully acknowledges financial support through Starting Grant no. StG-201194 (Consequences of Demographic Change) from the European Research Council (ERC). The authors thank Pearl Dystra, the editor of this special issue, and two anonymous reviewers of the journal for their helpful comments. 


\section{References}

Albertini, M., Kohli, M., and Vogel, C. (2007). Intergenerational transfers of time and money in European families: Common patterns - different regimes? Journal of European Social Policy 17(4): 319-334. doi:10.1177/0958928707081068.

Arrondel, L. and Masson, A. (2006). Altruism, exchange or indirect reciprocity: What do the data on reciprocity show? In: Kolm, S.C., and Ythier, J.M. (eds.). Handbook on the economics of giving altruism and reciprocity. North-Holland: Elsevier: 971-1053. doi:10.1016/S1574-0714(06)02014-8.

Atkinson, A.B. and Micklewright, J. (1992). Economic Transformation in Eastern Europe and the Distribution of Income. Cambridge, U.K.: Cambridge University Press.

Atkinson, M.P., Kivett, V.R., and Campbell, R.T. (1986). Intergenerational solidarity: An examination of a theoretical model. Journal of Gerontology 41(3): 408-416. doi:10.1093/geronj/41.3.408.

Barta, B., Klinger, A., Milt'enyi, K., and Vukovich, G. (1984). Fertility, Female Employment and Policy Measures in Hungary. Geneva: International Labour Office.

Billari, F.C. and Kohler, H.P. (2004). Patterns of lowest low fertility in Europe. Population Studies 58(2):161-176. doi:10.1080/0032472042000213695.

Blundell, R.W. and Smith, R.J. (1993). Simultaneous microeconometric models with censored or qualitative dependent variables. In: Maddala, G.S., Rao, C.R., and Vinoc, H.D. (eds.). Handbook of Statistics: Volume 11. Amsterdam: Elsevier:117-143. doi:10.1016/S0169-7161(05)80040-9.

Bodrova, V. and Anker, R. (1985). Working Women in Socialist Countries: The Fertility Connection. Geneva: International Labour Office.

Brainerd, E. (2000). Women in transition: Changes in gender wage differentials in Eastern Europe and the former Soviet Union. Industrial and Labor Relations Review 54(1): 138-162. doi:10.2307/2696036.

Brannen, J., Moss, P., and Mooney, A. (2004). Working and Caring over the Twentieth Century. Basingstoke: Palgrave Macmillan. doi:10.1057/9780230005716.

Bratti, M. (2003). Female labor force participation and marital fertility of Italian women: The role of education. Journal of Population Economics 16(3): 525-554. doi:10.1007/s00148-003-0142-5. 
Chiuri, M.C. (2000). Quality and demand of childcare and female labour supply in Italy. Labour 14(1):97-118. doi:10.1111/1467-9914.00126.

Del Boca, D. (2002). The effect of childcare and part time opportunities on participation and fertility decisions in Italy. Journal of Population Economics 15(3): 549-573. doi:10.1007/s001480100089.

Dimova, R. and Wolff, F.-C. (2008). Grandchildcare transfers by ageing immigrants in France: Intra-household allocation and labour market implications. European Journal of Population 24(3): 315-340. doi:10.1007/s10680-007-9122-x.

Dimova, R. and Wolff, F.-C. (2011). Do downward private transfers enhance maternal labour supply? Journal of Population Economics 24(3): 911-933. doi:10.1007/s00148-010-0305-0.

Ermisch, J.F. and Ogawa, N. (1996). Family structure, home time demands and the employment patterns of Japanese married women. Journal of Labour Economics 14(4): 677-702. doi:10.1086/209827.

Esping-Andersen, G. (1990). The three worlds of welfare capitalism. Cambridge: The Policy Press.

Esping-Andersen, G. (1999). Social Foundations of Postindustrial Economies. New York: Oxford University Press. doi:10.1093/0198742002.001.0001.

Fuller-Thomson, E. and Minkler, M. (2001). American grandparents providing extensive childcare to their grandchildren: Prevalence and profile. The Gerontologist 41(2): 201-209. doi:10.1093/geront/41.2.201.

Giarrusso, R., Stallings, M., and Bengtson, V.L. (1995). The "Intergenerational Stake" Hypothesis Revisited: Parent-Child Differences in Perception of Relationships 20 Years Later. In: Bengtson, V.L., Schaie, K.W., and Burton, L.M. (eds.): Adult Intergenerational Relations: Effects of Societal Change. New York: Springer: 227-263.

Gray, A. (2005). The changing availability of grandparents as carers and its implications for childcare policy in the UK. Journal of Social Policy 34(4): 557-577. doi:10.1017/S0047279405009153.

Greene, W. (1997). Econometric Analysis. Upper Saddle River, New Jersey: Prentice Hall.

Guzman, L. (1999). The use of grandparents as childcare providers. NSFH Working Paper. University of Wisconsin-Madison: Center for Demography and Ecology. 
Hagestad, G.O. (2006). Transfers between grandparents and grandchildren: The importance of taking a three-generation perspective. Zeitschrift für Familienforschung 18(3): 315-332.

Hagestad, G.O., and Herlofson, K. (2010). Transformations in the role of grandparents across welfare states. Gothenburg (Paper presented at the XVII ISA World Congress of Sociology, July 11-17 2010).

Hank, K. (2007). Proximity and contacts between older parents and their children: A European comparison. Journal of Marriage and Family 69(1): 157-173. doi:10.1111/j.1741-3737.2006.00351.x.

Hank, K. and Buber, I. (2009). Grandparents caring for their grandchildren: Findings from the 2004 survey of health, ageing and retirement. Journal of Family Issues 30(1): 53-73. doi:10.1177/0192513X08322627.

Hardin, J.W. (1996). Bivariate probit models. Stata Technical Bulletin 33(6): 15-20.

Hayslip, B. Jr. and Kaminski, P.L. (2005). Grandparents raising their grandchildren: A review of literature and suggestions for practice. The Gerontologist 45(2): 262-269. doi:10.1093/geront/45.2.262.

Keck, W., Hessel, P., and Saraceno, C. (2009). Database on Intergenerational Policy Indicators Methodological Report (http://www.multilinks-project.eu/uploads/pap ers/0000/0016/technical-report-version-1-2.pdf).

Konrad, K.A., Künemund, H., Lommerud, K.E., and Robledo, J.R. (2002). Geography of the Family. American Economic Review 92(4): 981-998. doi:10.1257/0002 8280260344551 .

Maddala, G.S. (1983). Limited-Dependent and Qualitative Variables in Econometrics. Cambridge: University Press.

McDonald, P. (2000). Gender equity in theories of fertility transition. Population and development review 26(3): 427-439. doi:10.1111/j.1728-4457.2000.00427.x.

Pagani, L. and Marenzi, A. (2008). The labour market participation of Sandwich Generation Italian women. Journal of Family and Economic Issues 29(3): 427444. doi:10.1007/s10834-008-9112-0.

Pebley, A.R. and Rudkin, L.L. (1999). Grandparents caring for grandchildren. What do we know? Journal of Family Issues 20(2): 218-242. doi:10.1177/01925 1399020002003. 
Reher, D. (1998). The history of the family in Spain: Past development, present realities, and future challenges. The history of the family 3(2): 125-136. doi:10.1016/S1081-602X(99)80238-3.

Rindfuss, R.R. and Brauner-Otto, S.R. (2008). Institutions and the transition to adulthood: Implications for fertility tempo in low-fertility settings. Vienna Yearbook of Population Research: 57-87. doi:10.1553/populationyearbook 2008 s57.

Robila, M. (2004). Families in Eastern Europe. Oxford: Elsevier.

Rossi, A.S. and Rossi, P.H. (1990). Of human bonding: parent child relations across the life course. New York: Aldine de Gruyter.

Salles, A., Rossier, C., and Brachet, S. (2010). Understanding the long term effects of family policies on fertility: The diffusion of different family models in France and Germany. Demographic Research 22(34): 1057-1096. doi:10.4054/ DemRes.2010.22.34.

Saraceno, C. (2008).Introduction: Intergenerational relations in families - A micromacro perspective. In: Saraceno, C. (ed.). Families, ageing and social policy. Intergenerational solidarity in European welfare states. Cheltenham: Edward Elgar: 1-19.

Saraceno, C., and Keck, W. (2008). The institutional framework of intergenerational family obligations in Europe: A conceptual and methodological overview. Deliverable 1.1 for the FP-7 funded project "How demographic changes shape intergenerational solidarity, well-being, and social integration: A multilinks framework".

Szelewa, D. and Polakowski, M.P. (2008). Who cares? Changing patterns of childcare in Central and Eastern Europe. Journal of European Social Policy 18(2): 115-131. doi:10.1177/0958928707087589.

Teplova, T. (2007). Welfare State Transformation, Childcare, and Women's Work in Russia. Social Politics 14(3): 284-322.

Tobio, C. (2001). Elever ses petits-enfants. In: Attias-Donfut, C. and Segalen, M. (eds.). Le siècle des grands-parents. Une génération phare, ici et ailleurs. Paris: Editions Autrement.

Vandell, D.L., McCartney, K., Owen, M.T., Booth, C., and Clarke-Stewart, A. (2003). Variations in chid care by grandparents during the first three years. Journal of 
Marriage and the Family 65(2): 375-381. doi:10.1111/j.1741-3737.2003.003 75.x.

Vikat, A., Spéder, Z., Beets, G., Billari, F.C., Bühler, C., Désesquelles, A., Fokkema, T., Hoem, J.M., MacDonald, A., Neyer, G., Pailhé, A., Pinnelli, A., and Solaz, A. (2007). Generations and Gender Survey (GGS): Towards a better understanding of relationships and processes in the life course. Demographic Research 17(14): 389-440. doi:10.4054/DemRes.2007.17.14.

Vlasblom, J.D. and Schippers, J.J. (2004). Increases in female labour force participation in Europe: Similarities and differences. European Journal of Population20(4): 375-392. doi:10.1007/s10680-004-5302-0.

Wilde, J. (2000). Identification of multiple equation probit models with endogenous dummy regressors. Economics Letters 69(3): 309-312. doi:10.1016/S01651765(00)00320-7. 
Aassve, Arpino \& Goisis: Grandparenting and mothers' labour force participation 